\title{
REVERSE LOGISTICS AS A COMPLEX SYSTEM: A CASE STUDY OF WASTE MANAGEMENT IN THE NORWEGIAN OFFSHORE PETROLEUM INDUSTRY
}

\author{
P. ENGELSETH \\ Department of Logistics, Molde University College, Norway.
}

\begin{abstract}
Waste management is usually considered just another form of reverse physical distribution. This case study points to uncertainties associated with operating a drill cuttings flow from offshore installations, through treatment on land, and onwards to its final form. The case description evokes a form of supply chain that is inherently complex. Contingency theory, focusing on interdependencies associated with interaction, is applied as approach to indicate how developing this waste flow as a complex system involves taking into account features of sequential, pooled and reciprocal interdependencies. Interaction should accordingly be tailored through analyzing these interdependencies found in the case.

Keywords: case study, contingency theory, interdependencies, Norwegian petroleum industry, reverse logistics, supply chain management.
\end{abstract}

\section{DRILL CUTTINGS AND COMPLEXITY}

This paper provides a single case study of waste management in the offshore oil and gas industry in Norway. The aim of this paper is to empirically ground the studied form of reverse logistics as a complex system specifically considering such operations from a contingency theory perspective. Reverse logistics is associated with flows of return goods, equipment and waste. In this study, focus is more specifically directed to operations regarding the waste management of drill cuttings. These are large-volume wastes that are extracted offshore at platforms or subsea facilities in association with drilling operations. Such drilling operations are associated with either exploration or production. In relation to oil and gas production, these operations are more or less continuous at offshore production platforms or subsea installations. Drilling in relation to ongoing production is required to increase the pressure of the oil or gas well extending the lifetime of such offshore facilities. Being offshore, this also increases logistical uncertainty due to unpredictable weather conditions and issues regarding coordinating different operations with other offshore operations at a location with very limited capacity measured in space; either a ship or a platform offshore. In addition, the drill cuttings flow is operated by a number of different agents, a factor that also contributes to increased complexity.

Previously Engelseth and Pettersen [1] had conceptually modelled offshore petroleum logistics as a complex system using agent- based modelling. This study provides, in addition to theoretically considering the role of contingency theory in complex systems thinking, a more focused consideration of a portion of this logistics system. A major contribution here is based on the writings of Thompson [2]. This implies considering interdependencies; more precisely sequential, reciprocal and pooled interdependencies (industrial particularities) and how this impacts process emergence as described in the case. Can contingency theory somehow provide guidance in managing complex reverse logistics supply chains? 


\section{COMPLEXITY FROM A CONTINGENCY THEORY VIEWPOINT}

The contingency theory perspective of organizational science originated with the work of Woodward [3] who points out that technologies directly determine differences in such organizational attributes as span of control, centralization of authority, and the formalization of rules and procedures. Contingencies are found in the environment of an organization, and may be regarded as its context. Context includes factors an organization directly interacts with such as technology, supply chain agents, customers and end-users, government and various organizations such as trade unions and interest groups. Morgan [4] states in a more recent work on contingency theory that it encompasses a set of fundamental views. This includes that organizations are considered as open systems; there is no optimal way of organizing and operating production such systems. In this context, the management needs therefore to align activities, pooling them and the resources used in these activities in search of good fit. According to Morgan [4], how one organizes varies between industries. Therefore, it is imminent from a contingency perspective to address industry-type particularities. Within this general approach to studying organizational structure and interaction, Fielder [5] developed a contingency model. This model focuses analytically on organizational behaviour in an environmentally contingent setting. He points out a three-dimension inquiry: (1) leader-member relationships, (2) degree of task structure, and (3) leader's position power. The three dimensions provide analytical tools that may be used to explain the inner functioning of environmentally contingent processes.

This study, however, focuses mainly on the works of Thompson [2]. He developed what may be characterized as a structural form of contingency theory. This concerns how different organizational structures, such as companies, interact systemically as agents in relation to each other in a network setting. In accordance with this structural contingency view, it is important to describe the industrial network and what characterizes systemic interaction in such a setting. Clearly, this is an approach that should prove useful in developing a detailed analytic understanding what constitutes 'supply chain management' (SCM). Taking this structural view, from the field of organizational sociology, Parson's [6] view of organizations as having three structural levels of responsibility and control: (1) technical, (2) managerial, and (3) institutional, is helpful. These levels indicate variation in what constitutes processes. Furthermore, these processes interact and need therefore to be coordinated. Rooted as it is in the works of Forrester's [7] studies of information distortion through tiers of supply chain agents ('the bullwhip effect'), SCM involves accordingly clearly systems thinking at core [8]. Managing the supply chain can therefore be considered as a unison coordinating of flows of service (intertwined goods and services products) and information.

Following Parson's [6] classification of organizational activity, taking an SCM perspective, the technical level concerns what organizations do; their 'production', the workflow. From a resource-based view of the firm perspective Penrose [9] states, moving away from the reductionist view of applying the term factor of production as commonplace in economics, that 'it is never resources themselves that are the "inputs" of the production process, but only the services that the resources render'. The term 'service' indicates accordingly what marketers term as 'product', the market tradeable production output, using a word that clearly depicts that the function of production is to please the customer. Service does not in this terminology denote an industrial sector, the 'services industry'. The managerial level involves therefore directing the flow of resources towards what constitutes a receivable service from the viewpoint of the customer. Following Perrow [10], the institutional level involves environmentally contingent patterns of behaviour. From an SCM perspective, production has a clear 
functional purpose; the quality supply of 'service' (using this term in line with Penrose [9]). Hammervoll [11] follows this line of customer-orientation in production by discerning between a production economy supported by an exchange economy. These two economic realms in supply chains are associated with transforming 'value' into a perceivable entity (material or immaterial) from a supply chain customer perspective; production associated with value as deliverable leading to 'value in use' and exchange associated with value in interaction. Value is an emergent perception. This evokes a question as to what constitutes 'value co-creation' in the context of economic exchange. 'Value' is associated with a meeting of production costs and qualities with customer-perceived benefits.

Value is created through exchanges in networks. The concept of 'exchange' encompasses a core feature of SCM that the flows are associated with transformation, and that value is produced through these flows. No firm is a secluded island. Production is dependent on the interaction both between and within forms. Integration is therefore a core value in SCM. However, this production is worthless if the production output is not valued by a recipient. Consumer perceptions are always changing. It is especially their expectations regarding service expectations that is the benchmark in their evaluation scheme. Value is accordingly impacted by two meeting realms of change. Value is in a constant state of flux. Production is associated with resource transformation. Exchange generates visualizations of supply purpose that may be exchanged and thereby negotiated:

Figure 1 depicts that the notion of 'value co-creation' is about coupling value perceptions among producers with customer value expectations. This interaction takes place before, during and after contracting a delivery. When set in the context of recurring purchases in a business relationship, this interaction is continuous. Taking a functionalistic view of supply chains, creating value is the explicit purpose of production. 'Co-creation' indicates purposeful inter-firm collaboration to technically interact in a business relationship. According to Croom et al. [12], the context of supply-related interaction refers to different levels of analysis, i.e. 'dyads', 'chain' or 'network'. Value co-creation is interpreted as dyadic interaction in the context of chains. Following Dill [13], the supply chain can be described as a task environment. 'The task environment, as information inputs, and tasks, as cognitive formulations to guide action...' [14]. Chains may, to varying degrees, be integrated denoting stronger or weaker degree of commonality in supply purpose. The supply chain is accordingly understood as the dynamic functionalistic context of the relationship dyad. Networks are then understood as a task environment encompassing dyads that are linked together regardless of degree of supply purpose integration. Agents are connected in networks. These connections can, however, be quite weak, include competitors, government etc. The chain is bound systemically with a common function while the network lacks this functional binding mechanism. In line with systems theory, various social relations entail interdependence between actors

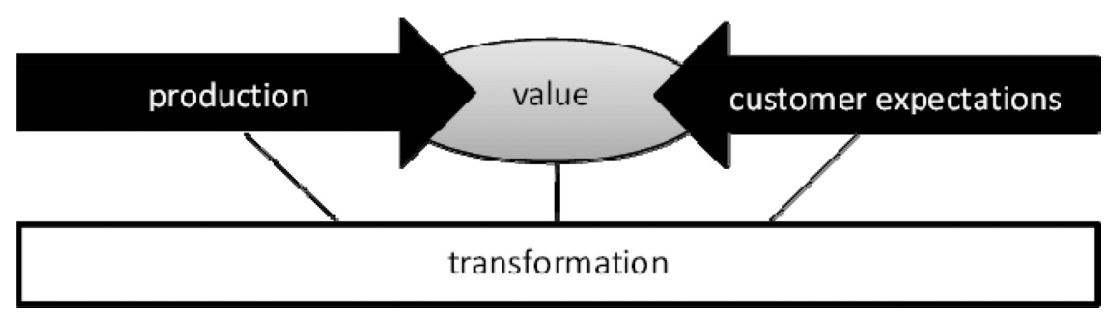

Figure 1: Value in a continuous state of flux. 
[15]. Following Pfeffer and Salancik [16] technical resource interdependency involves considering the role of power and trust. There is no automatic fit between different agents in a supply network. They must be integrated, and this is a strategically led administrative operation. It is emergent, but it is also wilful. Therefore, value co-creation is characterized by this wilfulness; a focused and functionally led use of time. The efficiency of such co-creation efforts in business relationships also depends on a certain level of achieved mutual trust between at least two firms in a common network.

Following Alderson's [17] functionalistic view of distribution, the purpose of production is associated in inter-organizational structures where goods are transformed providing time, place and form utility through a series of intermittently directed transformations. In physical distribution such chains of production agents, following Thompson [2], are involved in what he terms as a long-linked form of technology. This technology is found especially in manufacturing industries. Following Alderson's [17] transvection model of end-to-end marketing channels, production is described as piecemeal adjustment founded on stepwise management of sequentially interdependent transformations of goods.

This model may easily be interpreted as a complex understanding of production since the outcome flows of material are, in accordance with this view, multiple and sequentially interdependent, and may be understood as emergent. Management in the transvection is local and information-based. Interactions among supply chain agents to co-create values therefore dot the entire line of production from raw-material to consumption. Production is piecemeal an emergent to the degree the flow is locally managed by a coalition of complementary environmentally contingent agents. These agents have different contingencies. Following Thompson [2] production is characterized potentially by three types of interdependencies: (1) pooled, (2) sequential and (3) reciprocal. All production involves in some manner pooling recourses to produce. However, in physical distribution, sequential interdependencies are predominant. These interdependencies are associated with variation in technology to produce. Pooled interdependencies are associated with mediating technology, a need to combine resources to produce. In production, integration may be sought by automating the pooled interdependencies through increasing resource and activity standardization.

In cases of sequential interdependencies, the planned timing of production is imminent. If production is not successful, wastes occur and production output is impacted, possibly leading to insufficient production volume and quality creating a need to ration the output. Production is also hampered by uncertainty. Alderson's [17] transvection model is inherently associated with handling uncertainty by piecing up production as a chain of interlinked and coordinated flows. Production is wilfully designed to be tailored as an expression of market positioning or possibly simply because the technology used implies inherent reciprocal interdependency in the business relationship. In such cases, Thompson [2] advocates the use of what he terms as 'intensive technology'. In cases of reciprocal interdependency there is a pending need for mutual adjustment of managerial as well as production processes. It is

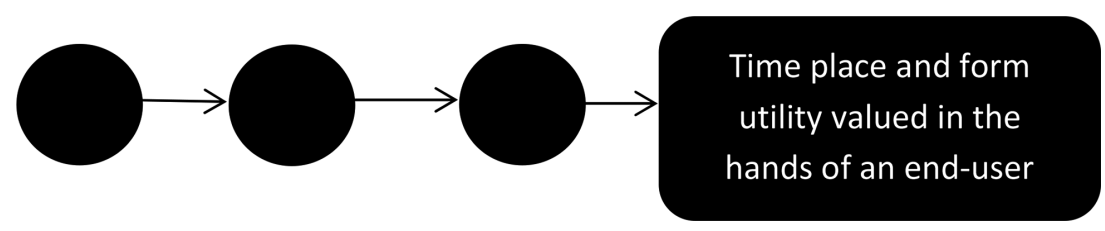

Figure 2: The transvection model. 
especially in cases of reciprocal interdependency that the business relationship must co-create. Developing co-creation should therefore in such cases focus on efficiencies in co-creation, especially since this relatively manual form of exchange implies heavy managerial costs in nations characterized by expensive administrative labour.

\section{METHOD}

This research of managing the supply chain associated with drill cuttings waste is carried out as a single case study. Following Miles and Huberman [18] and Yin [19] the case study research strategy is used when: (1) they make it possible to answer 'how' and 'why' research questions, (2) researchers cannot manipulate the behaviour involved during the research process and (3) researchers can seek a picture of the context the phenomenon is embedded in. A single case approach to evoke details at a micro-level [20], demanded in agent based modeling. Taylor and Fearne [21], Fernie and Thorpe [22] and Holweg and Pil [23] states that this method is appropriate for describing actors, structure and agency relations taking place through social interaction. Research was carried out by an executive of the petroleum logistics companies described in the case. This involved mainly applying own experiences. To secure objectivity, and more in-depth understanding of management and processes a few informal semi-structured interviews were conducted. The following case description provides an 'as-is' description of the waste management associated with offshore drill cuttings operations. Semi-structured interviews were carried out with informants and these interviews lasted on average for one hour. Interviews were taped and transcribed. A research protocol was created to register choices, main findings in individual interviews and provide preliminary analysis. This protocol was also used to design follow-up interviews. The study followed accordingly an emergent design where the research issue gradually became more precisely formulated as the research project evolved. The findings of this study are regarded transferable to similar industrial settings provided particularities of the industrial setting of this case study are carefully taken into consideration. Credibility is sought through providing a detailed case narrative where the level of interpretation is kept at a minimum level allowing for variation in interpretation. Furthermore, the narrative construct and analysis has been discussed with informants as well as subject to a peer review. Analysis has also been supplemented by empirical evidence and insights provided through three separate student-group term projects involving different topics related to petroleum logistics carried out by both undergraduate as well as graduate level students in logistics management. Applying a case study strategy involves limitations regarding the transferability of findings to other business cases.

\section{CASE DESCRIPTION}

The reverse logistics supply chain of drill cuttings is described in Fig. 3:

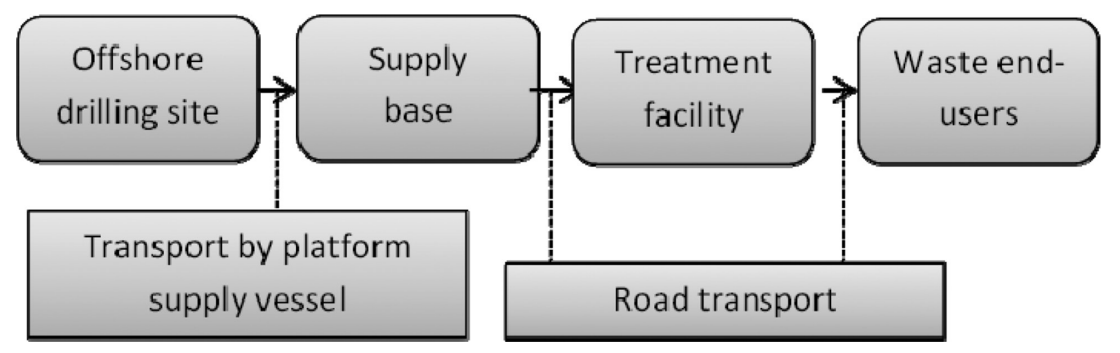

Figure 3: Drill cuttings reverse logistics. 
The drilling well at the offshore location itself can be viewed as a closed system. The drilling bit breaks rocks below the seabed moving deeper into the solid and, sometimes, frozen ground. Moving down deeper, new tubes are set in the hole and the area around is cemented to increase the casing's strength. When the borehole is drilled deep enough but there is still no oil or gas available, drilling operations are stopped. The well hole is filled up with drilling mud and uncased. Then, one of two following decisions can be made: continue drilling further and start the production, or block and leave it idle. When the drilling bit breaks the rock in the borehole reaching the oil and gas reservoir, the drilling mud lifts the soil, stone chips (sand, shale, limestone, granite) and pieces of rock (drill cuttings) come up to the surface. The size and texture of drill cuttings vary a lot. On board of the drilling rig there is a shale shaker and vibrating screens that process the drill cuttings. Drill cuttings are then pumped into tanks on offshore petroleum vessels. These are then when fully loaded offshore, transported to treatment at a specialized facility through the supply base. The offshore drilling site represents a collaboration between the petroleum company and the specialized company carrying out the drilling operations. The offshore drilling site, which may be a production platform, or an exploration drilling rig, the drill cuttings are extracted from the drilling pipes and pumped into tanks on the platform supply vessel. When drilling this means that a dedicated platform supply vessel must be available to store the drill cuttings waste. Such a tank measures $2.438 \mathrm{~m} * 2.591 \mathrm{~m} * 6.059 \mathrm{~m}$ (length*width*height), weighs up to 32.5 tons when fully loaded. The picture below shows an individual tank and the tanks loaded on a platform supply vessel.

When unloading at the supply base, a special movable crane is used to lift the tanks onto land. A reach stacker then lifts the tanks and delivers them to the special, predetermined location at the supply base for short-time storage. These are administered by a specialized waste management company at the supply base. They handle mainly the paperwork for these tanks. The drill cuttings, stored in tanks, are then transported a few kilometres by truck to a specialized treatment facility operated by another waste management company. When instructions are received, trucks are loaded for transportation using a reach stacker. When the trucks arrive at the treatment facility a special system is used on the truck to uplift the tank for empting (manually or automatically) following a specific procedure. The treatment of the drilling waste follows different procedures.

The following tree byproducts are created through treating the drill cuttings: (1) solids $(50 \%),(2)$ clean water $(40 \%)$ and (3) oil (10\%). The formation of solids received at the plant is different from what geologists are used to. Solids are not hazardous and cannot be pumped, thus, they are loaded to the cutting tanks and delivered to the nature as landfill by trucks. Water, when cleansed, they are pumped into the sea at the facility. Oil is used and sold in the

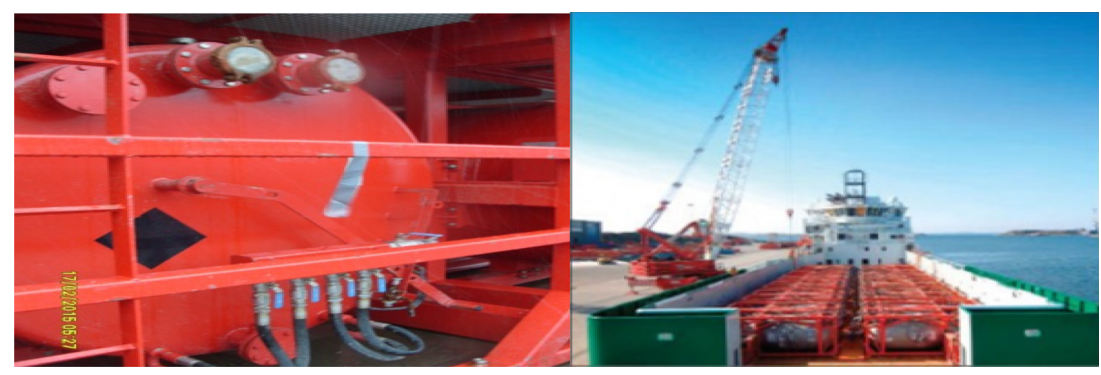

Figure 4: Drill cuttings in tanks. 
open market. The plant sells $90 \%$ of the oil to the industrial customers in Norway and $10 \%$ is used at the plant as alternative for electricity. Three times a year ships transport the oil produced through the treatment process.

\section{DISCUSSION AND CONCLUSION}

Supply chains, including the studied reverse logistics one, may be organizationally designed to be managed in many ways. The description provides grounds for considering this form of logistics as a complex system. Currently, it is managed following long-linked technology as a coordination problem with different stepwise managed activities. Each operation is described in detail through plans, but their initiation and finishing time is emergent. This case describes accordingly a project organization. Complexity is emperically evoked through the timed organizing of each drilling project. However, another form of complexity is associated with the features of the cuttings. They are natural substances and variations demand slight adaptation to handling.

The studied supply chain is described as a reverse logistics flow far upstream in the petroleum supply chain. It is understood as 'reverse logistics' since it handles wastes. The consumer is imminently far away from these wastes; so is any perception of end-user value. When conducting the investigation the informants spoke little about 'value' except when directly asked. There is reason to consider value more as an analytical tool than as a business management imperative for process development. There is no reason to teach the practitioners a new word to use as part of their professional terminology all the time 'value' is expressed in other ways. The transvection model provides some guidance here, since this form of production, in relation to the conception of value, is a portion of the production flow. This is a picture very distant from considering the production of manufactured consumer goods.

Value is important, though it is expressed in the business-to-business relationships using more exact technology-based terminologies. Since it is not the consumer value that is accounted for in this case, we need an alternative approach regarding what constitutes 'value' in this business-to-business relationship-type case. Thompson's [2] understanding of interdependencies provides a powerful analytical tool in understanding the logic of interaction in the studies drill cuttings reverse logistics supply chain. This production represents a form of physical distribution entailing that sequential interdependencies are prevalent. Such production may be regarded as a closed system and optimized. In this case, this is potentially perilous. In practice, the actors solve this problem of uncertainty by making plans that are changed at least once a day. In this manner the closed systems shows some flexibility. Reasons for change are many and are mainly associated with the drilling operation itself. Far offshore weather conditions, the drilling itself and routing of ships prove unpredictable. This indicates needs to develop pooled interdependencies as well as reciprocal interdependencies.

Pooling through improved use of mediating technology is founded on improved standardization in interaction, facilitating better use of information systems, including seamless real-time resource management. This development needs, however, to be complemented with the use of intense technology involved in the reciprocal interdependencies, when interaction through simply pooling is too difficult. Information technology may also support quality and economical mutual adjustments through improving how people communicate although they may be located at a distance. A virtual community may be established. Through viewing interaction in the studied case as combining sequential, pooled and reciprocal interdependencies, synergies should be sought regarding how people, tools and materials interact in the supply chain. 
Following the transvection model, the importance of local management can be considered. Managing this reverse flow of wastes may be viewed as a coordination of piecemeal emergent production steps. This also indicates that the nature of these flows as 'reverse' is of little importance from this analytical point of view. It simply describes that what is produced is not initially a product valued by an end-user. However, in the portion of the supply chain described through this case, wastes are transformed and marketed. Waste can therefore, in line with Engelseth [24], be associated with value. Waste may be considered when treated, as a product to the degree it is valued by a customer. This product value is a cognition that is co-created through local interaction, interactions that are sequentially interdependent. This provides a view of production as local decision making associated with stepwise managed productions. Customer value is in this picture clearly an emergent phenomenon. Further research should be directed to understanding how such supply chain development may be considered as a complex system from a contingency theory perspective and may be implemented in industrial practice.

\section{REFERENCES}

[1] Engelseth, P. \& Pettersen, T.M., Agent-based modelling of offshore upstream petroleum logistics. International Journal of Design \& Nature and Ecodynamics, 11(4), pp. 635-643, 2016.

https://doi.org/10.2495/DNE-V11-N4-635-643

[2] Thompson, J.D., Organizations in Action, McGraw Hill: New York, 1967.

[3] Woodward, J., Management and Technology, Her Majesty's Stationery Office: London, 1958.

[4] Morgan, G., Images of Organization, Thousand Oaks: Sage, 2007.

[5] Fiedler, F.E., A theory of leadership effectiveness. In Advances in Experimental Social Psychology, ed. L. Berkowitz, Academic Press: New York, 1964.

[6] Parsons, T., Structure and Processes in Modern Societies, The Free Press of Glencoe: New York. 1960.

[7] Forrester, J.W., Industrial Dynamics, Pegasus Communications: Waltham, MA, 1999.

[8] Lambert, D.M. \& Cooper, M.C., Issues in supply chain management. Industrial Marketing Management, 29(1), pp. 65-83, 2000. https://doi.org/10.1016/S0019-8501(99)00113-3

[9] Penrose, E.T., The theory of the growth of the firm, Oxford University Press: Oxford, UK, 1959.

[10] Perrow, C., Complex Organizations, A Critical Essay, Echo Point Books \& Media: Brattleboro, VT, 2014.

[11] Hammervoll, T., Service provision for co-creation of value: insights from exchangeand production economy perspectives. International Journal of Physical Distribution and Logistics Management, 44(1/2), 155-168, 2014.

[12] Croom, S., Romano, P. \& Giannakis, M., Supply chain management: an analytical framework for critical literature review. European Journal of Purchasing and Supply Management, 6(1), pp. 67-83, 2000. https://doi.org/10.1016/S0969-7012(99)00030-1

[13] Dill, W.R., Environment as an influence on managerial autonomy. Administrative Science Quarterly, 2(4), pp. 409-443, 1958.

https://doi.org/10.2307/2390794 
[14] Dill, W.R., Environment as an influence on managerial autonomy. Administrative Science Quarterly, 2(4), pp. 409-443, 1958.

https://doi.org/10.2307/2390794

[15] Emerson, R., Power-dependence relations. American Sociological Review, 27(1), pp. 31-41, 1962.

https://doi.org/10.2307/2089716

[16] Pfeffer, J., \& Salancik, G., The External Control of Organizations, Harper and Row: New York, 1978.

[17] Alderson, W., Dynamic Marketing Behavior: A Functionalist Theory of Marketing, Richard D. Irwin: Homewood, IL, 1965.

[18] Miles, M.B. \& Huberman, A.N., Qualitative Data Analysis, Thousand Oaks, CA: Sage, 1994.

[19] Yin, R.K., Case Studies Research: Design and Methods, Thousand Oaks, CA: Sage, 2009.

[20] Voss, C., Tsikriktsis, N. \& Frohlich, M., Case research in operations management. International Journal of Operations and Production Management, 22(2), pp. 195-219, 2002.

https://doi.org/10.1108/01443570210414329

[21] Taylor, D. \& Fearne, A., Towards a framework for improvement in the management of agri-food SCs. Supply Chain Management: An International Journal, 11(5), pp. 379384, 2006.

https://doi.org/10.1108/13598540610682381

[22] Fernie, S. \& Thorpe, A., Exploring change in construction: supply chain management. Engineering, Construction and Architectural Management, 14(4), pp. 319-333, 2007. https://doi.org/10.1108/09699980710760649

[23] Holweg, M. \& Pil, F.K., Theoretical perspectives on the coordination of supply chains. Journal of Operations Management, 26(3), pp. 389-406, 2008. https://doi.org/10.1016/j.jom.2007.08.003

[24] Engelseth, P., Developing the service value: a case study of waste management in offshore petroleum logistics. WIT Transactions on Ecology and the Environment, 202, pp. 135-146, 2016.

https://doi.org/10.2495/WM160131 